OPEN ACCESS

Edited by:

Brian Timothy Collins, School of Medicine, Georgetown

University, United States

Reviewed by:

Michael Andrew Samuels,

University of Miami, United States

Heng-Hong Li,

Georgetown University, United States

*Correspondence:

Sebastian Adeberg

sebastian.adeberg@

med.uni-heidelberg.de

Specialty section:

This article was submitted to

Radiation Oncology,

a section of the journal

Frontiers in Oncology

Received: 09 August 2019 Accepted: 29 November 2019 Published: 20 December 2019

Citation:

Adeberg S, Windisch $P$, Ehret $F$,

Baur M, Akbaba S, Held T,

Bernhardt D, Haefner MF, Krauss J,

Kargus $S$, Freudlsperger $C$, Plinkert $P$,

Flechtenmacher $C$, Herfarth $K$,

Debus J and Rieken S (2019) Intensity

Modulated Radiotherapy (IMRT) With

Carbon lon Boost in the Multimodal

Treatment of Salivary Duct Carcinoma.

Front. Oncol. 9:1420

doi: 10.3389/fonc.2019.01420

\section{Intensity Modulated Radiotherapy (IMRT) With Carbon lon Boost in the Multimodal Treatment of Salivary Duct Carcinoma}

\author{
Sebastian Adeberg ${ }^{1,2,3,4 *}$, Paul Windisch ${ }^{1}$, Felix Ehret ${ }^{1}$, Melissa Baur ${ }^{1}$, Sati Akbaba ${ }^{1,2}$, \\ Thomas Held ${ }^{1,2}$, Denise Bernhardt ${ }^{1,2}$, Matthias F. Haefner ${ }^{1,2}$, Juergen Krauss ${ }^{5}$, \\ Steffen Kargus ${ }^{6}$, Christian Freudlsperger ${ }^{6}$, Peter Plinkert ${ }^{7}$, Christa Flechtenmacher ${ }^{8}$, \\ Klaus Herfarth ${ }^{1,2,4}$, Juergen Debus ${ }^{1,2,3,4,5}$ and Stefan Rieken ${ }^{1,2,4}$ \\ ${ }^{1}$ Department of Radiation Oncology, Heidelberg University Hospital, Heidelberg, Germany, ${ }^{2}$ Heidelberg Institute for Radiation \\ Oncology, Heidelberg, Germany, ${ }^{3}$ Clinical Cooperation Unit Radiation Oncology, German Cancer Research Center (DKFZ), \\ Heidelberg, Germany, ${ }^{4}$ Heidelberg lon-Beam Therapy Center, Heidelberg, Germany, ${ }^{5}$ National Center for Tumor Diseases, \\ Heidelberg, Germany, ${ }^{6}$ Department of Oral and Maxillofacial Surgery, Heidelberg University Hospital, Heidelberg, Germany, \\ ${ }^{7}$ Department of Otorhinolaryngology, Heidelberg University Hospital, Heidelberg, Germany, ${ }^{8}$ Department of Pathology, \\ Heidelberg University Hospital, Heidelberg, Germany
}

Background: To assess outcomes and treatment related toxicity following intensity-modulated radiotherapy (IMRT) and a Carbon Ion Radiotherapy (CIRT) boost for salivary duct carcinoma (SDC).

Methods: Twenty-eight consecutive patients with SDC who underwent a postoperative $(82 \%)$ or definitive (18\%) radiation therapy between 2010 and 2017 were assessed in this retrospective single-center analysis. CIRT boost was delivered with median 18 Gy(RBE) in 6 daily fractions, followed by an TomoTherapy ${ }^{\circledR}$-based IMRT (median 54 Gy in 27 daily fractions). Treatment-related acute toxicity was assessed according to CTCAE Version 4.

Results: Tumors were most commonly located in the major salivary glands ( $n=25$; 89\%); 23 patients (82\%) received previous surgery (R0: 30\%; R1: 57\%; R2: 4\%; RX: 19\%). Median follow-up was 30 months. Four patients (14\%) experienced a local relapse and $3(11 \%)$ developed locoregional recurrence. The two-year local control (LC) and locoregional control (LRC) was 96 and 93\%, respectively. Median disease-free survival (DFS) was 27 months, metastasis-free survival (MFS) was 69 months, and overall survival (OS) was 93 months. Acute grade 3 toxicity occurred in 11 patients (mucositis, dermatitis, xerostomia; $n=2$ each (7\%) were the most common) and 2 osteonecroses of the mandibular (grade 3) occurred. No patients experienced grade $\geq 4$ toxicities.

Conclusions: Multimodal therapy approaches with surgery followed by IMRT and CIRT boost for SDC leads to good local and locoregional disease control. However, the frequent occurrence of distant metastases limits the prognosis and requires optimization of adjuvant systemic therapies.

Keywords: radiation therapy, bimodal radiotherapy, carbon ion radiotherapy, toxicity, salivary gland, intensitymodulated radiotherapy 


\section{INTRODUCTION}

SDC were first described by Kleinsasser and colleagues in 1968 as a separate group of "adenocarcinomas" of the salivary gland displaying a histopathological resemblance to ductal carcinoma of the breast; the World Health Organization recognized these tumors as a distinct tumor entity in $1991(1,2)$. Since then, SDC refer to rare but highly aggressive tumors originating from the ductal epithelium of major salivary glands (3). Malignant salivary gland tumors (MSGT) have an estimated annual incidence rate of 1 to 1.2 per 100,000 (4). SDC account for approximately $1 \%$ to $3 \%$ of all malignant salivary gland tumors and mostly occur during the fifth to seventh decade of life; men are predominantly affected (4-14). Current treatment options include surgery, systemic therapy, radiation and targeted therapy. Surgical management typically involves complete surgical resection and lymphadenectomy; depending on the tumor localization and stage, this can include parotidectomy, submandibular excision, ipsilateral, and contralateral neck dissection. Owing to its rarity and often poor response, the role of systemic therapies has only been investigated in case series and small clinical trials $(15,16)$.

Despite the advancements in surgery, systemic therapy and radiotherapy, the prognosis of SDC remains meager (6). Despite showing trends toward improved local control, especially the role of adjuvant radiotherapy remains unclear $(6,17-20)$. These tumors are currently treated in analogy to other MSGT. In the adjuvant setting, radiotherapy plays a role in patients with higher risk disease, e.g., perineural invasion (PNI), R+, T3/4 tumors. Additionally, definitive radiotherapy is a valuable alternative for unresectable cases. In the adjuvant setting, dose response relationships were described for both LRC (21) and LC (22) in MSGTs. Here, high-linear energy transfer (LET) radiation therapy (e.g., with charged particles such as carbon ions) can lead to improved tumor control rates in other head/neck malignancies as compared to standard photon therapy $(22,23)$. The objective of this retrospective, single-institutional study is to provide further clinical data and prognostic factors regarding intensity modulated radiotherapy (IMRT) with carbon ion radiotherapy (CIRT) in patients with SDC.

\section{MATERIALS AND METHODS}

\section{Patient Population}

Patient records, surgical reports, histological work-up, and radiotherapy treatment plans of patients with SDC who underwent IMRT-CIRT between August 2010 and November 2017 in the Department of Radiation Oncology, University Hospital and at the Heidelberg Ion-Beam Therapy Center (HIT) were evaluated retrospectively. A subset of patients (18\%) with locoregional advanced disease or unresectable received a primary radiotherapy.

\section{Radiation Therapy}

Treatment planning was performed using native and contrast enhanced CT/MRI. Patients were immobilized with individualized thermoplastic head masks. Technical details of CIRT are described elsewhere $(24,25)$. Treatment planning for CIRT was performed using Syngo PT Planning, Version 13 (Siemens, Erlangen, Germany) and TomoTherapy ${ }^{\circledR}$ Planning Station (Accuray, Sunnyvale, CA, USA) for photon radiotherapy planning. Patients were treated with a fixed horizontal beam/gantry for CIRT utilizing 1-2 coplanar/non-coplanar beams.

All patients received combined IMRT and CIRT. The base plan was performed using a helical intensitymodulated radiotherapy (IMRT) with daily image guidance (TomoTherapy $^{\circledR}$, Accuray, Sunnyvale, CA, USA), with 5 daily fractions per week (Figure 1).

\section{Target Volume Delineation and Dose Prescription}

Target delineation was based on native/contrast enhanced CT scans fused with contrast-enhanced MRI. Two clinical target volumes (CTV1/CTV2) were outlined. CTV2 comprised the macroscopic tumor and/or tumor bed. CTV1 included CTV2 as well as local growth patterns; ipsilateral nodal levels II-III were included into the CTV1 as well. A $3 \mathrm{~mm}$ margin was added to the CTVs to generate the planning target volumes (PTVs).

Organs at risk such as the spinal cord, contralateral parotid gland, temporomandibular joints, and the optic system were constrained per QUANTEC data (26). CTV1 received a median dose of $54 \mathrm{~Gy}$ (range: $50-56 \mathrm{~Gy}$ ) in $2 \mathrm{~Gy}$ daily doses (1.8 Gy to $2.0 \mathrm{~Gy}$ ) (median equivalent dose in $2 \mathrm{~Gy}$ fractions (EQD2) of $50 \mathrm{~Gy}$ ). CTV1 was to be covered by the $90 \%$ isodose line. A sequential CIRT boost was applied to the CTV2 utilizing an intensity-controlled active raster-scanning technique, in $3 \mathrm{~Gy}$ [relative biological effectiveness (RBE)] fractional doses up to a median combined EQD2 (Equivalent dose in 2Gy fractions) $=\mathrm{D} \frac{[\mathrm{d}+(\alpha / \beta)]}{[2+(\alpha / \beta)]}$ (where, $\mathrm{D}=$ total dose given in $\mathrm{Gy}, \mathrm{d}=$ dose per fraction in $\mathrm{Gy}$, and $\alpha / \beta=$ is assumed to be 2 ) of $78.5 \mathrm{~Gy}$ (range 78.5-80 Gy). We aimed for the CTV2 to be covered by the $95 \%$ isodose line. The following equation was used to calculate biologically effective dose $(\mathrm{BED})=n d\left(1+\frac{d}{\alpha / \beta}\right)$ (where $\mathrm{n}$ is the number of fractions, $\mathrm{d}$ is fractional dose (in Gy), and $\alpha / \beta$ is assumed to be 2). The total CIRT dose of 18-24 Gy (RBE) corresponds to a BED of 45-60 Gy.

\section{Follow Up}

Patients were monitored on treatment weekly with toxicity assessments (CTCAE classification v.4). Follow-up included a clinical examination by an otorhinolaryngologist and contrast enhanced MR-imaging of the head and neck every 3 months for the first 2 years after radiotherapy, every 6 months until the fifth year after treatment, and annually thereafter. Staging CTs were performed yearly to exclude distant metastases.

\section{Survival, Local, and Locoregional Control}

Local control (LC) and locoregional control (LRC) rates were calculated by Kaplan-Meier estimates, from the start of therapy until local tumor progression/death and/or nodal failure. Patients without tumor progression and patients lost to follow-up were censored. 

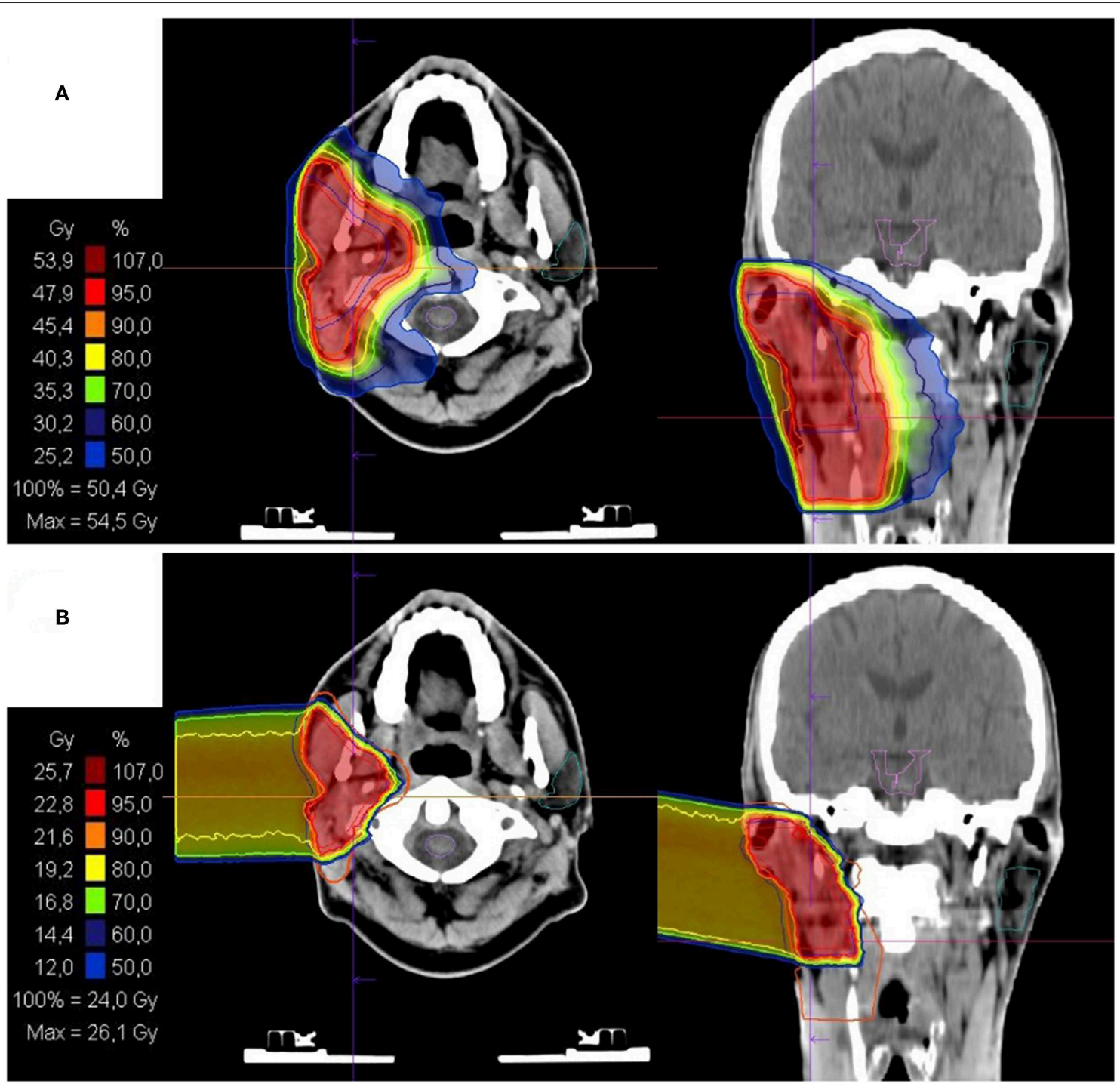

FIGURE 1 | Bimodal radiotherapy treatment plan: (A) intensity modulated radiotherapy (IMRT) base plan with 50Gy in 2Gy/fraction and (B) active raster-scanning carbon ion radiotherapy (CIRT) boost plan with 28Gy (RBE) in 3Gy (RBE)/fraction. Treatment was delivered as a definite radiotherapy in a patient with a recurrent rcT2 rcN2b cM0 salivary duct carcinoma (SDC) of the right parotid gland. CIRT was applied with one lateral beam. Histopathological work up revealed Her2neu and androgen receptor (AR) positivity. Therefore, the patient received an adjuvant therapy with trastuzumab and bicalutamide.

Metastasis-free survival (MFS) and disease-free survival (DFS) were calculated by Kaplan-Meier estimates, defined from the start of therapy until distant metastases occurred or progression/relapse at any location, respectively. Patients without events and those lost to follow-up were censored.

Overall Survival (OS) was calculated by Kaplan-Meier estimates, from the start of therapy until death or last contact (alive subjects were censored).

\section{Data Analysis}

The log-rank test for univariate analysis was performed to assess prognostic factors for survival. Statistical analyses were performed using SigmaPlot ${ }^{\mathrm{TM}}$ (Systat Software GmbH, Germany) software, and a $p$-value of $<0.05$ was considered statistically significant.

\section{RESULTS}

\section{Treatment Setup and Tumor Characteristics}

Detailed patient characteristics are depicted in Table 1. Overall 28 consecutive patients were included with a median age of 69 years (range $41-83$ years). $79 \%(n=22)$ of tumors were localized in the parotid gland.

Twenty-three patients $(82 \%)$ underwent surgical resection (parotidectomy, $n=17$; mastoidectomy, $n=4$; modified neck dissection, $n=20$ ) followed by postoperative radiotherapy. Five patients (18\%) received a definitive radiotherapy. Median clinical target volume (CTV) and planning target volume (PTV) dimension of the CIRT boost was 120cc (range 36-639cc) and $187 \mathrm{cc}$ (range $63-817 \mathrm{cc}$ ). Median time interval between surgery 
TABLE 1 | Clinical characteristics of the study cohort $(n=28)$.

\begin{tabular}{|c|c|}
\hline Parameter & Median (range or \%) \\
\hline Age (years) & $69(41-83)$ \\
\hline KPS & $90(60-100)$ \\
\hline \multicolumn{2}{|l|}{ Gender } \\
\hline Male & 25 (89\%) \\
\hline Female & $3(11 \%)$ \\
\hline \multicolumn{2}{|l|}{ Primary location } \\
\hline Parotid gland & 22 (79\%) \\
\hline Submandibular gland & $2(7 \%)$ \\
\hline Minor salivary glands & $2(7 \%)$ \\
\hline Sublingual gland & $1(4 \%)$ \\
\hline Lacrimal gland & $1(4 \%)$ \\
\hline \multicolumn{2}{|l|}{$T$ classification } \\
\hline $\mathrm{T} 1$ & $2(7 \%)$ \\
\hline $\mathrm{T} 2$ & $3(11 \%)$ \\
\hline T3 & $10(36 \%)$ \\
\hline T4 & $13(46 \%)$ \\
\hline \multicolumn{2}{|l|}{$\mathrm{N}$ classification } \\
\hline NO & $9(32 \%)$ \\
\hline $\mathrm{N} 1$ & $2(7 \%)$ \\
\hline N2 & $14(50 \%)$ \\
\hline N3 & $2(7 \%)$ \\
\hline$N X$ & $1(4 \%)$ \\
\hline \multicolumn{2}{|l|}{ M classification } \\
\hline M1 & $1(4 \%)$ \\
\hline \multicolumn{2}{|l|}{ PNI } \\
\hline Yes & $14(50 \%)$ \\
\hline No & $6(21 \%)$ \\
\hline n.e. & $8(29 \%)$ \\
\hline \multicolumn{2}{|l|}{ LV } \\
\hline Yes & 11 (39\%) \\
\hline No & $10(36 \%)$ \\
\hline n.e. & $7(37 \%)$ \\
\hline \multicolumn{2}{|l|}{ Resection status } \\
\hline $\mathrm{RO}$ & $7(30 \%)$ \\
\hline $\mathrm{R} 1$ & $13(57 \%)$ \\
\hline $\mathrm{R} 2$ & $1(4 \%)$ \\
\hline $\mathrm{Rx}$ & $2(9 \%)$ \\
\hline \multicolumn{2}{|l|}{ Her2neu } \\
\hline Positive & $14(50 \%)$ \\
\hline Negative & $10(36 \%)$ \\
\hline n.e. & $4(14 \%)$ \\
\hline
\end{tabular}

PNI, perineural invasion; LV, Iymphovascular invasion; n.e., not examined; KPS, Karnofsky performance status.

Numbers may not add to $100 \%$ owing to rounding and multiple categorizations for single specimens.

and commencement of radiotherapy was 57 days (range: 30-135 days). Complete surgical resection (R0) was achieved in 7 patients (30\%). The majority of tumors initially presented at advanced stages (T3, $n=10,36 \%$ and T4, $n=13,46 \%$ ) and with lymph node involvement (N1, $n=2,7 \%$; N2, $n=14,50 \%$; N3, $n=2$, $7 \%)$. PNI (50\%) and lymphovascular invasion (LVI) (39\%) was common. Her2neu was positive in 14/24 tested patients (58\%). tumor tissues were positive for androgen receptors Most (19/23, $83 \%)$. Adjuvant systemic therapy with the antiandrogen agent bicalutamide was delivered to 7 patients and bicalutamide with trastuzumab in 5 patients.

\section{Survival and Local Control}

After a median follow-up of 30 months (range: 8-109 months), 17 patients $(61 \%)$ were still alive. Local tumor progression was observed in 3 patients (11\%) and nodal failure was observed in 4 patients (14\%). Median LC and LRC were not reached (Figure 2). The actuarial 2-year LC and LRC was 96 and 93\%, respectively. Distant metastases occurred in 9 patients (32\%) over the course of disease. Median metastasis-free survival (MFS) was 69 months (range: 4-102).

The most frequent location of distant metastases was pulmonary (21\%) and osseous (14\%) areas. Metachronous distant metastases occurred in 4 patients (21\%). In one patient, preexisting bipulmonary metastases were progressive. Overall, the median disease-free survival (DFS) was 27 months (range: 4107 months). Median overall survival (OS) was 93 months (range: 9-109 months) (Figure 3). Five cases who underwent definitive radiotherapy did not experience a local relapse during followup, but 3 of 5 experienced distant metastases after 6, 7, and 15 months. Patient and tumor characteristics between definitive and postoperative treated patients did not differ significantly. Here median DFS $(p=0.23)$ and OS $(p=0.58)$ did not show statistical differences, even though patient cohorts were rather small for comparison.

\section{Prognostic Factors}

On univariate analysis larger CTV and PTV dimension of the CIRT boost (both continuous variates) were prognostic for impaired DFS $(p=0.026$ and $p=0.003)$, MFS $(p=0.006$ and $p=0.007)$ and $\mathrm{OS}(p=0.005$ and $p=0.005)$. Nodal involvement was prognostic for poor DFS $(p=0.022)$, MFS $(p=0.044)$ (Figure 4) and showed a trend toward impaired OS $(p=0.059)$. LVI was associated with impaired DFS ( $p=$ $0.045)$ and $\mathrm{OS}(p=0.041)$ (Figure 4). Other known prognostic factors like T-stage, Her2neu, PNI, age, adjuvant systemic therapies and resection status did not show a correlation with any endpoint.

\section{Treatment Related Toxicities}

Acute grade 1 and 2 fatigue, mucositis, xerostomia, and dermatitis were commonly observed in the study cohort. Ten acute grade 3 toxicities [two each (7\%) of mucositis, dermatitis, xerostomia; and one each (3\%) of dysphagia, odynophagia, dysgeusia, nausea/emesis] occurred in 7 patients (25\%). In 11 patients (58\%) a preexisting facial palsy remained stable during/after radiotherapy. Regarding late adverse event, two osteonecroses of the mandibular jaw occurred 24 and 32 months after radiotherapy. In one patient a surgical intervention was necessary (grade 3 ) and led to satisfactory long-term results. Overall, no acute or late grade $\geq 4$ toxicities were reported. 
TABLE 2 | Overview of the literature regarding management of salivary duct carcinoma.

\begin{tabular}{|c|c|c|c|c|c|c|c|c|}
\hline Authors/Study & Year & $\begin{array}{c}\text { Sample size } \\
\text { (number of } \\
\text { patients) }\end{array}$ & $\begin{array}{l}\text { Median time } \\
\text { of follow-up } \\
\text { (months) }\end{array}$ & $\begin{array}{c}\text { Local } \\
\text { control (\%) }\end{array}$ & $\begin{array}{l}\text { Received surgery } \\
\text { (number of } \\
\text { patients) }\end{array}$ & $\begin{array}{c}\text { Received } \\
\text { radiotherapy } \\
\text { (number of patients) }\end{array}$ & $\begin{array}{l}\text { Node positive } \\
\text { tumors (number of } \\
\text { tumors) }\end{array}$ & Results \\
\hline Afzelius et al. (27) & 1987 & 12 & NR & NR & 12 & 12 & 5 & $\begin{array}{l}\text { Average survival: } 21.7 \text { months } \\
\text { DOD: } 7 / 12 \text { (58\%) }\end{array}$ \\
\hline Brandwein et al. (28) & 1990 & 12 & NR & NR & 12 & 6 & 8 & DOD: 45\% (5/11) within 10 years \\
\hline Delgado et al. (29) & 1993 & 15 & NR & NR & 15 & 9 & 10 & DOD: 53\% (8/15) \\
\hline Kumar et al. (30) & 1993 & 11 & NR & NR & 11 & 10 & 3 & NR \\
\hline Barnes et al. (31) & 1994 & 13 & 24 (for 12/13) & 92 & 13 & 5 & 7 & DOD: 23\% (3/13) \\
\hline Grenko et al. (32) & 1995 & 12 & NR & NR & 12 & 8 & 8 & $\begin{array}{l}\text { DOD: } 33 \%(4 / 12) \\
\text { Median } 12.5 \text { months }\end{array}$ \\
\hline Lewis et al. (9) & 1996 & 26 & NR & 65 & 25 & 15 & 17 & $\begin{array}{l}\text { DOD within } 3 \text { years: } 77 \%(20 / 26) \\
\text { Mean survival: } 36 \text { months } \\
\text { 2-year survival: } 58 \% \\
\text { 5-year survival: } 30 \%\end{array}$ \\
\hline Guzzo et al. (15) & 1997 & 26 & 36 & 64 & 25 & 18 & 15 & $\begin{array}{l}\text { 2-year survival: } 43 \% \\
\text { 5-year survival: } 11.5 \%\end{array}$ \\
\hline Hosal et al. (33) & 2003 & 15 & 34 & 79 & 15 & 14 & 11 & $\begin{array}{l}\text { DOD: } 57 \%(8 / 14) \\
\text { Mean time to recurrence: } \\
17 \text { months }\end{array}$ \\
\hline Jaehne et al. (7) & 2005 & 50 & NR & 52 & 49 & 36 & 28 & $\begin{array}{l}\text { Average OS: } 56.2 \text { months } \\
\text { Average time from first treatment to } \\
\text { local recurrence: } 17.4 \text { months } \\
\text { DOD: } 56 \% \text { (28/50) } \\
\text { 5-year survival rate stage I: } 42 \% \\
\text { 5-year survival rate stage II: } 40 \% \\
\text { 5-year survival rate stage III: } 30.8 \% \\
\text { 5-year survival rate stage IV: } 23.2 \%\end{array}$ \\
\hline Kim et al. (20) & 2012 & 35 & 48 & 63 (5-year) & 35 & 35 & 26 & $\begin{array}{l}\text { Cause-specific death rate: } 31.4 \% \\
\text { 5-year survival: } 55.1 \% \\
\text { 5-year DFS: } 47.4 \%\end{array}$ \\
\hline Shinoto et al. (19) & 2013 & 25 & 44 (for $14 / 25$ ) & 67 (5-year) & 25 & 25 & 15 & $\begin{array}{l}\text { 5-year DFS: } 45 \% \\
\text { 5-year survival: } 47 \%\end{array}$ \\
\hline Jayaprakash et al. (6) & 2014 & 228 & $\begin{array}{c}53 \text { (for } \\
\text { survivors) }\end{array}$ & NR & 223 & 166 & 111 & $\begin{array}{l}\text { DOD: } 30 \% \text { (70/228) after } 10 \text { years } \\
\text { Median OS: } 79 \text { months } \\
\text { 5-year DSS: } 64 \% \\
\text { 10-year DSS: } 56 \%\end{array}$ \\
\hline Shi et al. (34) & 2014 & 38 & 39 & NR & 30 & 14 & 14 & $\begin{array}{l}\text { 5-year DSS: 45\% } \\
\text { 5-year RFS: 30\% }\end{array}$ \\
\hline Roh et al. (35) & 2014 & 56 & 71 & 87 & 44 & 47 & 40 & $\begin{array}{l}\text { Median DMFS: } 36 \text { months } \\
\text { Median DSS: } 48 \text { months } \\
\text { Median OS: } 48 \text { months }\end{array}$ \\
\hline
\end{tabular}


TABLE 2 | Continued

\begin{tabular}{|c|c|c|c|c|c|c|c|c|}
\hline Authors/Study & Year & $\begin{array}{c}\text { Sample size } \\
\text { (number of } \\
\text { patients) }\end{array}$ & $\begin{array}{l}\text { Median time } \\
\text { of follow-up } \\
\text { (months) }\end{array}$ & $\begin{array}{c}\text { Local } \\
\text { control (\%) }\end{array}$ & $\begin{array}{l}\text { Received surgery } \\
\text { (number of } \\
\text { patients) }\end{array}$ & $\begin{array}{c}\text { Received } \\
\text { radiotherapy } \\
\text { (number of patients) }\end{array}$ & $\begin{array}{c}\text { Node positive } \\
\text { tumors (number of } \\
\text { tumors) }\end{array}$ & Results \\
\hline
\end{tabular}

Median OS: 48 month Median PFS: 16 months 5-year DMFS rate: $36 \%$

5 -year DSS rate: $44 \%$

5-year OS rate: $42 \%$

5-year PFS rate: $29 \%$

Nakashima et al. (36)

2015

26

31

NR

26

Huang et al. (10)

2015

11

NR

NR

11

8

5-year OS rate: $48.1 \%$

Mean OS time: 72.8 months

2-year OS rate: $75 \%$

Schmitt et al. (37)

2015

28

NR

NR

28

Median DFS: 3.24 years

Median OS: 4.65 years

5-year DFS: $49.2 \%$

5-year OS: 49.3\%

Luk et al. (8)

2016

23

26

NR

23

Johnston et al. (38)

83 (5-year)

53

Otsuka et al. (39)

2016

141

Gilbert et al. (40)

Mifsud et al. (41)

DOD: 43\% (10/23)

5-year DFS: 36\% 5-year DSS: 43\%

5-year distant control: 48\%

5-year OS: $43 \%$

3-year DFS: $38.2 \%$

3-year OS: $70.5 \%$

Median DFS: 2.7 years

Median OS: 3.1 years

Median OS: 49 months

3-year OS: $35.5 \%$

3-year RFS: $34.4 \%$

5-year DSS: $42 \%$

5-year OS: 32\%

5-year RFS: 35\%

5-year DFS: 58.1\%

5-year DMFS: $65.2 \%$

5-year OS: $56.9 \%$

2-year OS: $93 \%$

Median DFS: 23 months

Median DMFS: 26 months

Median OS: 51 months

10-month DFS: $75 \%$

20-month DFS: $25 \%$

Anwer et al. (43)

2018

12

12

NR

11

Current study

2019

28

30

96

23

28

Median DFS: 27 months

Median DMFS: 69 months

Median OS: 93 months

Grad 3 toxicity: $21 \%$ 

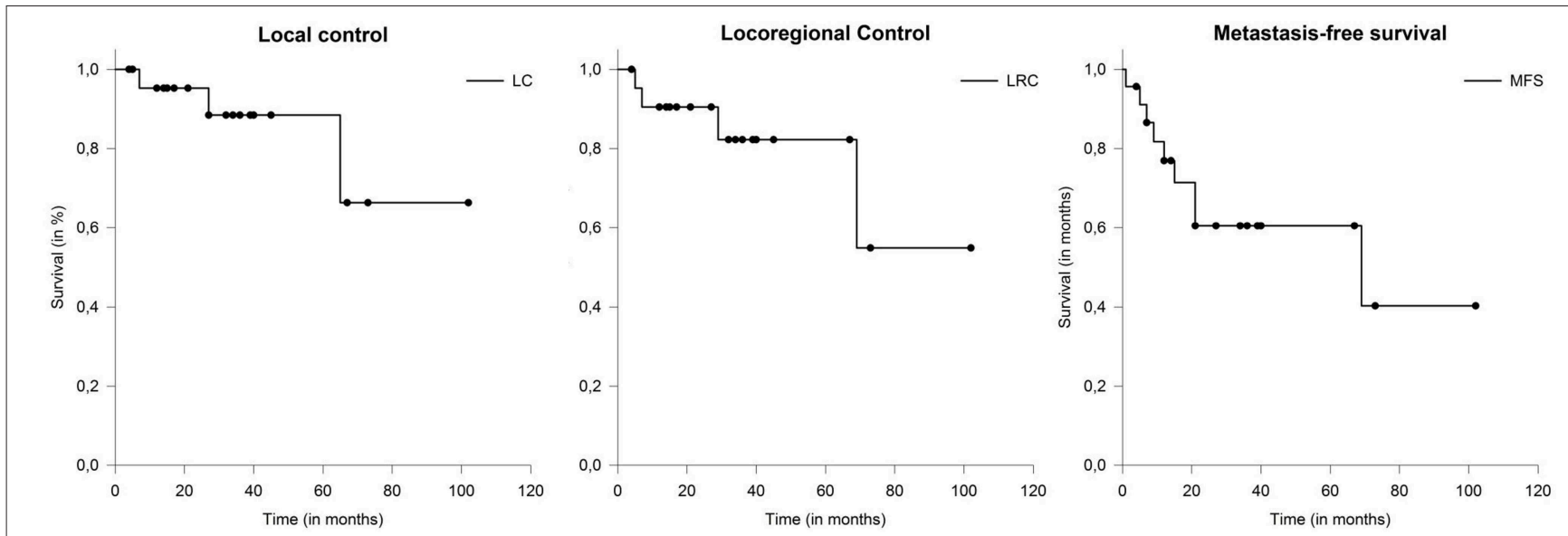

FIGURE 2 | The actuarial 2-year LC and LRC was 96 and 93\%, respectively. Metastasis-free survival (MFS) in patients with salivary duct carcinoma (SDC) 69 months.
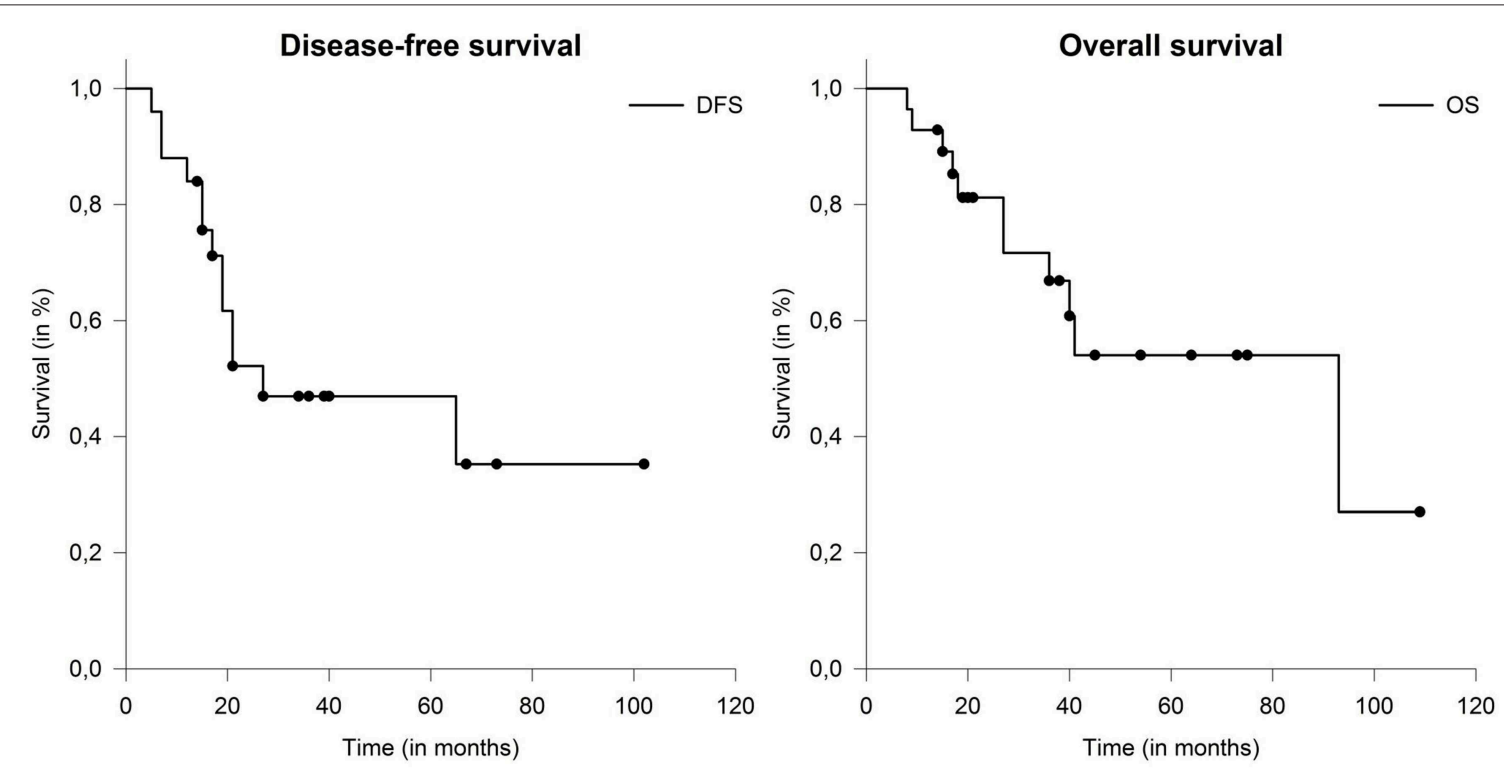

FIGURE 3 | Median disease-free survival (DFS) and overall survival (OS) in patients with salivary duct carcinoma (SDC) were 27 and 93 months.

\section{DISCUSSION}

Although surgery combined with IMRT and CIRT resulted in appropriate LC and LRC, prognosis of patients with SDC is limited by the high rate of distant metastases underlined by a poor MFS in our cohort.

However, even when definitively treated, SDCs are linked to a meager prognosis with most of the patients dying within 5 years of diagnosis $(7,9,14,39,40,44)$. High rates of local recurrence (15-55\%) and distant metastases (33-62\%) account for the worse outcome (33). Local approaches should thus include radical surgical resection e.g., with parotidectomy and neck dissection whenever possible.

Postoperative radiotherapy in SDC is mainly performed as extrapolations from head and neck tumors including MSGT.
However, larger series that focus on the predictors and outcome after radiotherapy are lacking. Smaller series report of 5-year LC, DFS, and OS rates of 67,45 , and $47 \%$ after adjuvant radiotherapy with a median photon dose of $60 \mathrm{~Gy}$. The authors advise including nerves tracked to the skull base if PNI is presented (19). The addition of radiotherapy can reduce local recurrence rates from approximately 30 to $10 \%$ without impacting OS (21). Summarizing various single institution experiences, LC rates were encouraging after surgery and postoperative radiotherapy $(17,20)$.

Overall a benefit for radiotherapy dose escalation for MSGTs has been shown, for instance in adenoid cystic carcinoma (ACC) $(45,46)$. The data for the subgroup of SDC, however, is unclear. The current study presents the first data of advanced radiation techniques with IMRT and high-LET CIRT. 

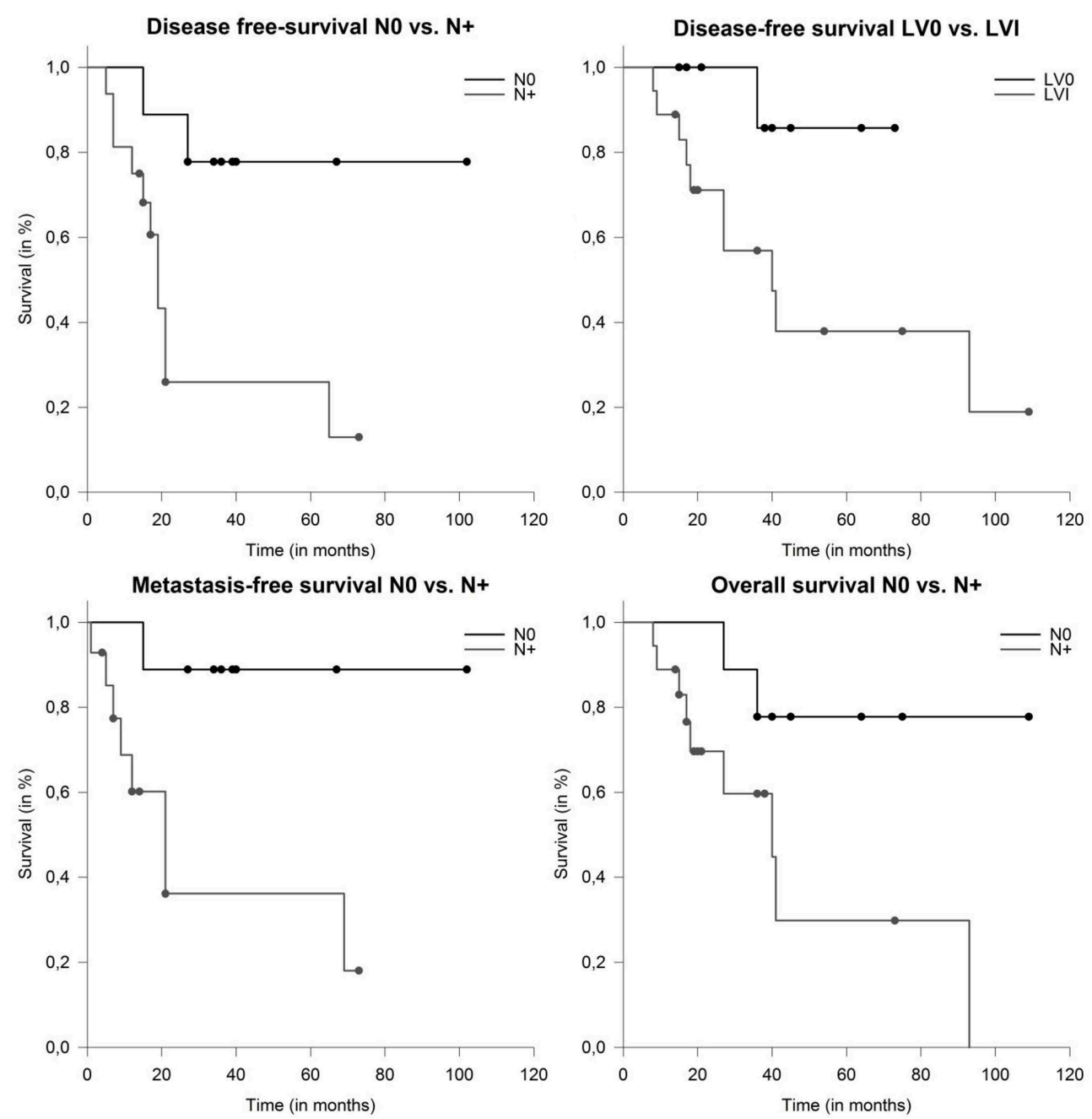

FIGURE 4 | Median disease-free survival (DFS) depending on nodal involvement $(p=0.009)$ and lymphovascular involvement $(p=0.045)$. Metastasis-free survival and overall survival (OS) in patients with salivary duct carcinoma (SDC) depending on nodal involvement $(p=0.02$ and $p=0.039$ ).

With regard to local control in these relatively radioresistant tumors, high-LET radiotherapy seems to be beneficial. In this context, the biophysical advantages with its steep dose-gradient and superior relative biological effectiveness (RBE) allow for safer dose-escalation, like previously described in other tumor entities of the head and neck (47-52) Furthermore the high physical conformity, compared to photons and decreased lateral scattering as with other particles lead to decreased dose to normal tissue (53). This potentially translates into improved local control by means of safer dose escalation combined with improved sparing of organs at risk. Despite negative prognostic factors in the majority of patients in our cohort, LC and LRC rates of 96 and $93 \%$ after 2 years were favorable compared to other reports in the literature $(7,9,15,36,43)$. Our experiences of relatively low DFS and MFS are supported by previous series $(6,7,14,39,40)$.

In the largest database analysis of 228 patients with SDC treated between 1973 and 2008, lymph node involvement, age, large tumor size, and tumor grade were associated with worse disease-specific survival (median OS was 79 months) (6). In another large national registry study in the Netherlands, OS, DFS, and MFS were 51, 23, and 26 months. Herein, the majority of patients (68\%) initially presented with lymph node involvement, which is in line with our findings that greater boost volumes and nodal involvement were associated with inferior DFS and OS (14).

Clinical outcomes of 141 patients of a multi-institutional study cohort in Japan, where 59\% of patients underwent postoperative radiotherapy, revealed that $\mathrm{N}+$ was associated with lower OS and that the most common treatment failure was distant metastases in $39 \%$ (39). These results are consistent with the current study and underline the urgent need for improved systemic therapy.

A histopathological review of 75 cases, with the majority $(81.3 \%)$ of patients receiving (chemo)radiotherapy, showed that PNI, LVI, and/or extracapsular spread were negative prognostic factors. The addition of chemotherapy to radiotherapy did not improve outcomes (40). 
Additionally, there is no consensus on the role of systemic therapy in SDC in general (54-56). However, androgen receptors are found in 80 to $90 \%$ of SDC, as well as 30 to $70 \%$ expressing the human epidermal growth factor receptor (EGFR) and Her2neu, making the tumor a target for androgen deprivation therapy and monoclonal antibodies like cetuximab or trastuzumab, respectively (14, 40, 57-61). Recently, adjuvant androgen deprivation in patients with androgen receptor positive SDC has been shown do have a positive impact on DFS and seems to influence OS (62). In a histopathologic study of 50 SDC cases, expression of Her2neu was associated with a more aggressive course of disease (7). In this study, a significant proportion of the assessed tumors were positive for Her2neu and a subset received non-standardized trastuzumab as adjuvant treatment. Furthermore, the majority of tumors assessed were positive for androgen receptors, and received bicalutamide. However, the treatment period, intervals, and combinations thereof were extremely heterogenous, likely why no effect of any systemic therapy in the current analysis could be shown. Moreover, 50 to $70 \%$ of tumors expressing the EGFR-receptor may show benefit to EGFR-targeted therapy $(56,61,63,64)$. The high tendency for aggressive growth and patterns of failure demand the optimization of adjuvant treatment regimens. However, prospective trials remain elusive due to the rarity of the disease, even in a multicenter setting. A detailed list of series on surgical treatment and radiotherapy for SDC is provided in Table 2.

Toxicities herein were acceptable. In a retrospective analysis of patients with minor MSGT, several higher-grade toxicities were described, including dysphagia, xerostomia and also hearing loss, which were influenced by the target volume (65). Schulz-Ertner et al. described severe toxicity rates under $5 \%$ if radiotherapy is performed with modern techniques like IMRT combined with CIRT (66). Data of high-LET radiotherapy with neutrons produce late toxicities in approximately $10 \%$ (67), which is higher compared to these data, although follow up was relatively short herein. Furthermore, the retrospective design and the small patient sizes may add additional biases. In addition, adjuvant therapies were non-standardized and unmonitored herein. Despite these limitations, this is the first study to evaluate advanced radiation techniques using high-LET radiotherapy in SDC. Overall, the combination of surgical resection with neck

\section{REFERENCES}

1. Kleinsasser O, Klein HJ, Hubner G. [Salivary duct carcinoma. A group of salivary gland tumors analogous to mammary duct carcinoma]. Archiv fur klinische und experimentelle Ohren- Nasen- und Kehlkopfheilkunde. (1968) 192:100-5.

2. Udager AM, Chiosea SI. Salivary duct carcinoma: an update on morphologic mimics and diagnostic use of androgen receptor immunohistochemistry. Head Neck Pathol. (2017) 11:288-94. doi: 10.1007/s12105-0170798-x

3. Barnes L, Eveson JW, Reichart, P, Sidaransky, D. Pathology and Genetics of Head and Neck Tumours. WHO Classification of Tumours, $3 r d$ Edition. Lyon: IARC Press (2005).

4. Boukheris H, Curtis RE, Land CE, Dores GM. Incidence of carcinoma of the major salivary glands according to the WHO classification, 1992 to 2006: a population-based study in the United States. Cancer Epidemiol Biomarkers Prev. (2009) 18:2899-906. doi: 10.1158/1055-9965 dissection followed by dose-escalated radiotherapy with IMRT and CIRT leads to good LC. However, the high rate of distant metastases requires optimization of systemic therapies.

\section{CONCLUSIONS}

Overall, the combination of surgical resection with neck dissection followed by dose-escalated radiotherapy with IMRT and CIRT leads to good local control rates. Larger tumor size and nodal involvement were associated with inferior disease control and survival. However, the limiting factor in patients with SDC is the high rate of distant mestastases, which is why adjuvant therapy need to optimized.

\section{DATA AVAILABILITY STATEMENT}

All datasets generated for this study are included in the article.

\section{ETHICS STATEMENT}

The study was conducted in accordance with the Declaration of Helsinki. The study was approved by the ethics committee University Heidelberg (S-421/2015). Due to the retrospective nature of the evaluation of the performed standard therapy and the sole use of anonymized data, no study specific informed consent was necessary according to the local ethical guidelines.

\section{AUTHOR CONTRIBUTIONS}

SAd and PW: conceptualization. SAd, PW, and FE: methodology. SAd: formal analysis. SAd, PW, SAk, MB, TH, and DB: investigation. SAd and FE: writing-original draft preparation. SAd, JD, and SR: supervision. All authors: writing-review and editing.

\section{FUNDING}

This work was supported by Heidelberg University young investigator grants to DB. We thank Thomas Mielke for excellent technical assistance.

5. Tamaki T, Dong Y, Ohno Y, Sobue T, Nishimoto H, Shibata A. The burden of rare cancer in Japan: application of the RARECARE definition. Cancer Epidemiol. (2014) 38:490-5. doi: 10.1016/j.canep.2014.07.014

6. Jayaprakash V, Merzianu M, Warren GW, Arshad H, Hicks WL, Rigual NR, et al. Survival rates and prognostic factors for infiltrating salivary duct carcinoma: analysis of 228 cases from the surveillance, epidemiology, and end results database. Head Neck. (2014) 36:694-701. doi: 10.1002/hed. 23350

7. Jaehne M, Roeser K, Jaekel T, Schepers JD, Albert N, Loning T. Clinical and immunohistologic typing of salivary duct carcinoma: a report of 50 cases. Cancer. (2005) 103:2526-33. doi: 10.1002/cncr.21116

8. Luk PP, Weston JD, Yu B, Selinger CI, Ekmejian R, Eviston TJ, et al. Salivary duct carcinoma: clinicopathologic features, morphologic spectrum, and somatic mutations. Head Neck. (2016) 38(Suppl. 1):E183847. doi: $10.1002 /$ hed. 24332

9. Lewis JE, McKinney BC, Weiland LH, Ferreiro JA, Olsen KD. Salivary duct carcinoma. Clinicopathologic and immunohistochemical review 
of 26 cases. Cancer. (1996) 77:223-30. doi: 10.1002/(SICI)10970142(19960115)77:2<223::AID-CNCR1 >3.0.CO;2-N

10. Huang X, Hao J, Chen S, Deng R. Salivary duct carcinoma: a clinopathological report of 11 cases. Oncol Lett. (2015) 10:337-41. doi: 10.3892/ol.20 15.3176

11. Breinholt H, Elhakim MT, Godballe C, Andersen LJ, Primdahl H, Kristensen CA, et al. Salivary duct carcinoma: a Danish national study. J Oral Pathol Med. (2016) 45:664-71. doi: 10.1111/jop.12426

12. Simpson RH. Salivary duct carcinoma: new developmentsmorphological variants including pure in situ high grade lesions; proposed molecular classification. Head Neck Pathol. (2013) 7(Suppl. 1):S48-58. doi: 10.1007/s12105-013-0456-x

13. Wee DT, Thomas AA, Bradley PJ. Salivary duct carcinoma: what is already known, and can we improve survival? J Laryngol Otol. (2012) 126(Suppl. 2):S2-7. doi: 10.1017/S0022215112000412

14. Boon E, Bel M, van Boxtel W, van der Graaf WTA, van Es RJJ, Eerenstein SEJ, et al. A clinicopathological study and prognostic factor analysis of 177 salivary duct carcinoma patients from The Netherlands. Int J Cancer. (2018) 143:758-66. doi: 10.1002/ijc.31353

15. Guzzo M, Di Palma S, Grandi C, Molinari R. Salivary duct carcinoma: clinical characteristics and treatment strategies. Head Neck. (1997) 19:126-33. doi: 10. 1002/(SICI)1097-0347(199703)19:2<126::AID-HED7>3.0.CO;2-6

16. Takahashi H, Tada Y, Saotome T, Akazawa K, Ojiri H, Fushimi C, et al. Phase II trial of trastuzumab and docetaxel in patients with human epidermal growth factor receptor 2-positive salivary duct carcinoma. J Clin Oncol. (2019) 37:125-34. doi: 10.1200/JCO.18.00545

17. Kim TH, Kim MS, Choi SH, Suh YG, Koh YW, Kim SH, et al. Postoperative radiotherapy in salivary ductal carcinoma: a single institution experience. Radiat Oncol J. (2014) 32:125-31. doi: 10.3857/roj.2014.32.3.125

18. Haderlein M, Scherl C, Semrau S, Lettmaier S, Hecht M, Erber R, et al. Impact of postoperative radiotherapy and HER2/new overexpression in salivary duct carcinoma: a monocentric clinicopathologic analysis. Strahlentherapie und Onkologie. (2017) 193:961-70. doi: 10.1007/s00066-017-1196-8

19. Shinoto M, Shioyama Y, Nakamura K, Nakashima T, Kunitake N, Higaki Y, et al. Postoperative radiotherapy in patients with salivary duct carcinoma: clinical outcomes and prognostic factors. I Radiat Res. (2013) 54:92530. doi: $10.1093 / \mathrm{jrr} / \mathrm{rrt} 026$

20. Kim JY, Lee S, Cho KJ, Kim SY, Nam SY, Choi SH, et al. Treatment results of post-operative radiotherapy in patients with salivary duct carcinoma of the major salivary glands. Br J Radiol. (2012) 85:e94752. doi: $10.1259 / \mathrm{bjr} / 21574486$

21. Terhaard $\mathrm{CH}$. Postoperative and primary radiotherapy for salivary gland carcinomas: indications, techniques, and results. Int $J$ Radiat Oncol Biol Phys. (2007) 69(Suppl. 2):S52-55. doi: 10.1016/j.ijrobp.2007. 04.079

22. Garden AS, Weber RS, Morrison WH, Ang KK, Peters LJ. The influence of positive margins and nerve invasion in adenoid cystic carcinoma of the head and neck treated with surgery and radiation. Int J Radiat Oncol Biol Phys. (1995) 32:619-26. doi: 10.1016/0360-3016(95)00122-F

23. Jensen AD, Nikoghosyan AV, Poulakis M, Höss A, Haberer T, Jäkel $O$, et al. Combined intensity-modulated radiotherapy plus raster-scanned carbon ion boost for advanced adenoid cystic carcinoma of the head and neck results in superior locoregional control and overall survival. Cancer. (2015) 121:30019. doi: $10.1002 / \mathrm{cncr} .29443$

24. Combs SE, Burkholder I, Edler L, Rieken S, Habermehl D, Jäkel O, et al. Randomised phase I/II study to evaluate carbon ion radiotherapy versus fractionated stereotactic radiotherapy in patients with recurrent or progressive gliomas: the CINDERELLA trial. BMC Cancer. (2010) 10:533. doi: 10.1186/1471-2407-10-533

25. Rieken S, Habermehl D, Haberer T, Jaekel O, Debus J, Combs SE. Proton and carbon ion radiotherapy for primary brain tumors delivered with active raster scanning at the Heidelberg Ion Therapy Center (HIT): early treatment results and study concepts. Radiat Oncol. (2012) 7:41. doi: 10.1186/1748-717X-7-41

26. Bentzen SM, Constine LS, Deasy JO, Eisbruch A, Jackson A, Marks LB, et al. Quantitative Analyses of Normal Tissue Effects in the Clinic (QUANTEC): an introduction to the scientific issues. Int J Radiat Oncol Biol Phys. (2010) 76(Suppl. 3):S3-9. doi: 10.1016/j.ijrobp.2009.09.040
27. Afzelius LE, Cameron WR, Svensson C. Salivary duct carcinoma-a clinicopathologic study of 12 cases. Head Neck Surgery. (1987) 9:1516. doi: 10.1002/hed.2890090304

28. Brandwein MS, Jagirdar J, Patil J, Biller H, Kaneko M. Salivary duct carcinoma (cribriform salivary carcinoma of excretory ducts). A clinicopathologic and immunohistochemical study of 12 cases. Cancer. (1990) 65:2307-14. doi: 10. 1002/1097-0142(19900515)65:10<2307::AID-CNCR2820651024>3.0.CO;2-1

29. Delgado R, Vuitch F, Albores-Saavedra J. Salivary duct carcinoma. Cancer. (1993) 72:1503-12. doi: 10.1002/1097-0142(19930901)72:5<1503::AIDCNCR2820720503>3.0.CO;2-K

30. Kumar RV, Kini L, Bhargava AK, Mukherjee G, Hazarika D, Shenoy AM, et al. Salivary duct carcinoma. I Surg Oncol. (1993) 54:1938. doi: $10.1002 /$ jso. 2930540315

31. Barnes L, Rao U, Krause J, Contis L, Schwartz A, Scalamogna P. Salivary duct carcinoma. Part I. A clinicopathologic evaluation and DNA image analysis of 13 cases with review of the literature. Oral Surg Oral Med Oral Pathol. (1994) 78:64-73. doi: 10.1016/0030-4220(94)90119-8

32. Grenko RT, Gemryd P, Tytor M, Lundqvist PG, Boeryd B. Salivary duct carcinoma. Histopathology. (1995) 26:2616. doi: 10.1111/j.1365-2559.1995.tb01440.x

33. Hosal AS, Fan C, Barnes L, Myers EN. Salivary duct carcinoma. Otolaryngol Head Neck Surg. (2003) 129:720-5. doi: 10.1016/S0194-5998(03)01386-X

34. Shi S, Fang Q, Liu F, Zhong M, Sun C. Prognostic factors and survival rates for parotid duct carcinoma patients. J Cranio Maxillo Fac Surg. (2014) 42:1929-31. doi: 10.1016/j.jcms.2014.08.001

35. Roh JL, Lee JI, Choi SH, Nam SY, Kim SO, Cho KJ, et al. Prognostic factors and oncologic outcomes of 56 salivary duct carcinoma patients in a single institution: high rate of systemic failure warrants targeted therapy. Oral Oncol. (2014) 50:e64-6. doi: 10.1016/j.oraloncology.2014.08.010

36. Nakashima T, Yasumatsu $R$, Toh $S$, Hashimoto $K$, Shinoto $M$, Nakamura $\mathrm{K}$, et al. Is there a role of adjuvant treatment for salivary duct carcinoma? J Laryngol Otol. (2015) 129 (Suppl. 2):S98-101. doi: 10.1017/S0022215114002965

37. Schmitt NC, Sharma A, Gilbert MR, Kim S. Early T stage salivary duct carcinoma: outcomes and implications for patient counseling. Otolaryngol Head Neck Surg. (2015) 153:795-8. doi: 10.1177/0194599815601659

38. Johnston ML, Huang SH, Waldron JN, Atenafu EG, Chan K, Cummings BJ, et al. Salivary duct carcinoma: treatment, outcomes, and patterns of failure. Head Neck. (2016) 38 (Suppl. 1):E820-6. doi: 10.1002/hed.24107

39. Otsuka K, Imanishi Y, Tada Y, Kawakita D, Kano S, Tsukahara K, et al. Clinical outcomes and prognostic factors for salivary duct carcinoma: a multi-institutional analysis of 141 patients. Ann Surg Oncol. (2016) 23:203845. doi: 10.1245/s10434-015-5082-2

40. Gilbert MR, Sharma A, Schmitt NC, Johnson JT, Ferris RL, Duvvuri U, et al. A 20-year review of 75 cases of salivary duct carcinoma. JAMA Otolaryngol Head Neck Surg. (2016) 142:489-95. doi: 10.1001/jamaoto.2015.3930

41. Mifsud M, Sharma S, Leon M, Padhya T, Otto K, Caudell J. Salivary duct carcinoma of the parotid: outcomes with a contemporary multidisciplinary treatment approach. Otolaryngol Head Neck Surg. (2016) 154:104146. doi: 10.1177/0194599816636812

42. Beck ACC, Lohuis P, Al-Mamgani A, Smit LA, Klop WMC. Salivary duct carcinoma: evaluation of treatment and outcome in a tertiary referral institute. Eur Arch Oto-Rhino-laryngol. (2018) 275:1885-92. doi: 10.1007/s00405-018-5000-x

43. Anwer AW, Faisal M, Adeel M, Waqas O, Abu Bakar M, Qadeer S, et al. Clinicopathological behavior and treatment-related outcome of rare salivary duct carcinoma: the shaukat khanum memorial cancer hospital experience. Cureus. (2018) 10:e3139. doi: 10.7759/cureus.3139

44. Gnepp DR HJ, Simpson RHW, Eveson J. Salivary and lacrimal glands. In: Gnepp DR, editor. Diagnostic Surgical Pathology of the Head and Neck. 2 ed. Philadelphia: Saunders Elsevier (2009). doi: 10.1016/B978-1-4160-2589-4.00006-1

45. Laramore GE, Krall JM, Griffin TW, Duncan W, Richter MP, Saroja KR, et al. Neutron versus photon irradiation for unresectable salivary gland tumors: final report of an RTOG-MRC randomized clinical trial. Radiation Therapy Oncology Group. Medical Research Council. Int J Radiat Oncol Biol Phys. (1993) 27:235-40. doi: 10.1016/0360-3016(93)90233-L 
46. Douglas JG, Koh WJ, Austin-Seymour M, Laramore GE. Treatment of salivary gland neoplasms with fast neutron radiotherapy. Arch Otolaryngol Head Neck Surg. (2003) 129:944-8. doi: 10.1001/archotol.129.9.944

47. Akbaba S, Mock A, Hoerner-Rieber J, Held T, Katayama S, Forster $\mathrm{T}$, et al. Treatment outcome of a combined dose-escalated treatment regime with helical tomoTherapy(R) and active raster-scanning carbon ion boost for adenocarcinomas of the head and neck. Front Oncol. (2019) 9:755. doi: 10.3389/fonc.2019.00755

48. Akbaba S, Lang K, Held T, Herfarth K, Rieber J, Plinkert P, et al. Carbon-ion radiotherapy in accelerated hypofractionated active raster-scanning technique for malignant lacrimal gland tumors: feasibility and safety. Cancer Manag Res. (2019) 11:1155-66. doi: 10.2147/CMAR.S190051

49. Akbaba S, Lang K, Bulut OC, Held T, Rieken S, Plinkert P, et al. The role of organ- and function-preserving radiotherapy in the treatment of adenoid cystic carcinoma of the larynx. Head Neck. (2019) 41:220814. doi: 10.1002/hed.25678

50. Akbaba S, Heusel A, Mock A, Held T, Lang K, Hoerner-Rieber J, et al. The impact of age on the outcome of patients treated with radiotherapy for mucoepidermoid carcinoma (MEC) of the salivary glands in the head and neck: a 15-year single-center experience. Oral Oncol. (2019) 97:11523. doi: 10.1016/j.oraloncology.2019.08.018

51. Akbaba S, Ahmed D, Lang K, Held T, Mattke M, Hoerner-Rieber J, et al. Results of a combination treatment with intensity modulated radiotherapy and active raster-scanning carbon ion boost for adenoid cystic carcinoma of the minor salivary glands of the nasopharynx. Oral Oncol. (2019) 91:3946. doi: 10.1016/j.oraloncology.2019.02.019

52. Adeberg S, Akbaba S, Lang K, Held T, Verma V, Nikoghosyan A, et al. The Phase 1/2 ACCEPT trial: concurrent cetuximab and intensity modulated radiation therapy with carbon ion boost for adenoid cystic carcinoma of the head and neck. Int J Radiat Oncol Biol Phys. (2019). doi: 10.1016/j.ijrobp.2019.09.036

53. Weber U, Kraft G. Comparison of carbon ions versus protons. Cancer J. (2009) 15:325-32. doi: 10.1097/PPO.0b013e3181b01935

54. Dimery IW, Legha SS, Shirinian M, Hong WK. Fluorouracil, doxorubicin, cyclophosphamide, and cisplatin combination chemotherapy in advanced or recurrent salivary gland carcinoma. J Clin Oncol. (1990) 8:105662. doi: 10.1200/JCO.1990.8.6.1056

55. Lewis AG, Tong T, Maghami E. Diagnosis and management of malignant salivary gland tumors of the parotid gland. Otolaryngol Clin North Am. (2016) 49:343-80. doi: 10.1016/j.otc.2015.11.001

56. Williams MD, Roberts DB, Kies MS, Mao L, Weber RS, El-Naggar AK. Genetic and expression analysis of HER-2 and EGFR genes in salivary duct carcinoma: empirical and therapeutic significance. Clin Cancer Res. (2010) 16:2266-74. doi: 10.1158/1078-0432.CCR-09-0238

57. D'Heygere E, Meulemans J, Vander Poorten V. Salivary duct carcinoma. Curr Opin Otolaryngol Head Neck Surgery. (2018) 26:142-51. doi: 10.1097/MOO.0000000000000436

58. Masubuchi T, Tada Y, Maruya S, Osamura Y, Kamata SE, Miura K, et al. Clinicopathological significance of androgen receptor, HER2, Ki-67 and EGFR expressions in salivary duct carcinoma. Int J Clin Oncol. (2015) 20:3544. doi: 10.1007/s10147-014-0674-6

59. Takase S, Kano S, Tada Y, Kawakita D, Shimura T, Hirai H, et al. Biomarker immunoprofile in salivary duct carcinomas: clinicopathological and prognostic implications with evaluation of the revised classification. Oncotarget. (2017) 8:59023-35. doi: 10.18632/oncotarget.19812
60. Shimura T, Tada Y, Hirai H, Kawakita D, Kano S, Tsukahara K, et al. Prognostic and histogenetic roles of gene alteration and the expression of key potentially actionable targets in salivary duct carcinomas. Oncotarget. (2018) 9:1852-67. doi: 10.18632/oncotarget.22927

61. Keller G, Steinmann D, Quaas A, Grunwald V, Janssen S, Hussein K. New concepts of personalized therapy in salivary gland carcinomas. Oral Oncol. (2017) 68:103-13. doi: 10.1016/j.oraloncology.2017.02.018

62. van Boxtel W, Locati LD, van Engen-van Grunsven $\mathrm{ACH}$, Bergamini C, Jonker MA, Fiets E, et al. Adjuvant androgen deprivation therapy for poorrisk, androgen receptor-positive salivary duct carcinoma. Eur J Cancer. (2019) 110:62-70. doi: 10.1016/j.ejca.2018.12.035

63. Fan CY, Melhem MF, Hosal AS, Grandis JR, Barnes EL. Expression of androgen receptor, epidermal growth factor receptor, and transforming growth factor alpha in salivary duct carcinoma. Arch Otolaryngol Head Neck Surg. (2001) 127:1075-9. doi: 10.1001/archotol.127.9.1075

64. Williams MD, Roberts D, Blumenschein GR Jr, Temam S, Kies MS, Rosenthal DI, et al. Differential expression of hormonal and growth factor receptors in salivary duct carcinomas: biologic significance and potential role in therapeutic stratification of patients. Am J Surg Pathol. (2007) 31:164552. doi: 10.1097/PAS.0b013e3180caa099

65. Salgado LR, Spratt DE, Riaz N, Romesser PB, Wolden S, Rao S, et al. Radiation therapy in the treatment of minor salivary gland tumors. Am J Clin Oncol. (2014) 37:492-7. doi: 10.1097/COC.0b013e31827e54e5

66. Schulz-Ertner D, Nikoghosyan A, Didinger B, Münter M, Jäkel O, Karger $\mathrm{CP}$, et al. Therapy strategies for locally advanced adenoid cystic carcinomas using modern radiation therapy techniques. Cancer. (2005) 104:33844. doi: $10.1002 / \mathrm{cncr} .21158$

67. Stannard C, Vernimmen F, Carrara H, Jones D, Fredericks S, Hille J, et al. Malignant salivary gland tumours: can fast neutron therapy results point the way to carbon ion therapy? Radiother Oncol. (2013) 109:2628. doi: 10.1016/j.radonc.2013.08.013

Conflict of Interest: SAd and DB received grants from Accuray International Sàrl outside the submitted work. DB received grants from Novocure outside the submitted work. JD received grants from CRI-The Clinical Research Institue $\mathrm{GmbH}$, View Ray Inc., Accuray International Sàrl, Accuray Incorporated, RaySearch Laboratories AB, Vision RT limited, Merck Serono GmbH, Astellas Pharma $\mathrm{GmbH}$, Astra Zeneca $\mathrm{GmbH}$, Solution Akademie $\mathrm{GmbH}$, Ergomed PLC Surrey Research Park, Siemens Healthcare GmbH, Quintiles GmbH, Pharmaceutecal Research Associates $\mathrm{GmbH}$, Boehringer Ingelheim Pharma GmbH Co, PTW-Freiburg Dr. Pychlau GmbH, Nanobiotix AA outside the submitted work.

The remaining authors declare that the research was conducted in the absence of any commercial or financial relationships that could be construed as a potential conflict of interest.

Copyright (c) 2019 Adeberg, Windisch, Ehret, Baur, Akbaba, Held, Bernhardt, Haefner, Krauss, Kargus, Freudlsperger, Plinkert, Flechtenmacher, Herfarth, Debus and Rieken. This is an open-access article distributed under the terms of the Creative Commons Attribution License (CC BY). The use, distribution or reproduction in other forums is permitted, provided the original author(s) and the copyright owner(s) are credited and that the original publication in this journal is cited, in accordance with accepted academic practice. No use, distribution or reproduction is permitted which does not comply with these terms. 